\title{
ACCREDITATION OF HIGHER EDUCATION IN DIFFERENT COUNTRIES AND IMPROVEMENTS IN TURKISH HIGHER EDUCATION $^{1}$
}

\begin{abstract}
Berna ASLAN*
ABSTRACT. The study investigates accreditation of higher education in different countries and improvements in Turkish higher education. England, USA and Japan higher education systems are critisized according to accreditation procedures. At the end it is summarized that the accreditation of higher education is carried out for recognition, quality improvement or financial support from the government.
\end{abstract}

Keywords: Higher education, accreditation, quality in higher education, accreditation of higher education in different countries.

\footnotetext{
${ }^{1}$ Extracted from a $\mathrm{PhD}$. thesis "Accreditation in Teacher Education and a Model for Accreditation of Teacher Education in Turkey" prepared in Ankara University Institute of Educational Sciences

${ }^{*}$ Res. Assist. Dr. Berna Aslan, Ankara University Faculty of Educational Sciences, barslan@education.ankara.edu.tr
} 


\section{SUMMARY}

Today the "quality assurance" issue is started to be discussed in many higher education institutions. Higher education systems have many reasons to start quality assurance process. Financial issues, quality improvement requirements are some reasons for this movement.

"Accreditation" is one way for universities to provide "quality assurance". Other ways are "evaluation", "benchmarking" and "auditing". Accreditation is an evaluation process in which an institution or a program is assessed according to pre-defined standards. It requires a certain and pre defined process to follow. The other ways for providing "quality assurance" in higher education institutions differ from an accreditation process in some ways.

Aim of the present study is to investigate different higher education systems, having experience in accreditation procedures. In this context England, USA and Japan higher education systems are evaluated according to accreditation implications. The following research questions are investigated:

- How is the accreditation of the higher education in England?

- How is the accreditation of the higher education in USA?

- How is the accreditation of the higher education in Japan?

Also the improvements in Turkish higher education are analysed in the study.

In this descriptive study, different higher education systems are described according to implication of accreditation.

The results indicate that accreditation in higher education serves different purposes as quality improvement, competition between institutions, getting a respective place in the academic world and funding.

Quality assurance mechanisms are very complicated in many countries. Although in USA accreditation carried out by private accreditation institutions; in England, accreditation carried out by the government. In England the Quality Assurance Agency (QAA) is responsible for the accreditation. Also there is external evaluation for teacher education programs, undergraduate and graduate programs in England. Although the employees are appointed by the government, QAA works as relatively independent institution. But in England the system is more look like audience rather than accreditation. 
In USA independent accreditation institutions carry out accreditation but these institutions are also accredited or recognised by government. In USA there are three accreditation systems as: regional accreditation institutions, national accreditation institutions and specific accreditation institutions.

Regional accreditation is necessity for universities in USA. However, in Japan there isn't any necessity for accreditation. All higher education institutions are part of the Ministry of Education, Culture, Sport, Science and Technology (MEXT) in Japan and there is no relation between funding and accreditation. JUAA (Japan University Accreditation Association) accreditation provides universities with respect in the academic world. In recent years, Japan higher education institutions have given more importance on accreditation and evaluation.

Regarding to Turkish higher education, some studies are done at departmental level but for the general higher education we may mention more about "evaluation" rather than "accreditation". Studies about accreditation may improve the understanding of "quality" in Turkish universities but we should compose more external evaluation systems to recognize the problems truly. 


\title{
ÇEŞITLII ÜLKELERDE YÜKSEKÖĞRETIMMDE AKREDITTASYON VE TÜRK YÜKSEKÖĞRETIMIINDEKI GELIŞMELER ${ }^{2}$
}

\author{
Berna ASLAN*
}

\begin{abstract}
ÖZ. $\mathrm{Bu}$ çalışmada çeşitli ülkelerdeki yükseköğretimde akreditasyon uygulamaları ve Türk yükseköğretimindeki gelişmeler ele alınmıştır. İngiltere, Amerika Birleşik Devletleri ve Japonya'da yükseköğretimde akreditasyonun nasıl olduğu, akreditasyon süreçleri incelenmiştir. Sonuçta akreditasyonun yükseköğretimde kalitenin sağlanması, öğrenci fonlarından yararlanabilme, akademik arenada saygınlık kazanma gibi çeşitli amaçlarla yapıldığı görülmüştür.
\end{abstract}

Anahtar Sözcükler: Yükseköğretim, akreditasyon, yükseköğretimde kalite, farklı ülkelerde yükseköğretimin akreditasyonu.

\footnotetext{
${ }^{2}$ Ankara Üniversitesi Eğitim Bilimleri Enstitüsü’nde Prof. Dr. Mehmet A. Kısakürek danışmanlığında yapılmış "Öğretmen Yetiştirmede Akreditasyon ve Türkiye için Bir Model Önerisi” başlıklı doktora tezinin bir bölümünden yararlanılarak hazırlanmıştır.

*Araş. Gör. Dr., Ankara Üniversitesi, Eğitim Bilimleri Fakültesi, barslan@education.ankara.edu.tr
} 


\section{GİRIŞ}

Tarihsel süreç içerisinde üniversitelerin amacı ve işleyişi toplumların beklentilerine paralel bir şekilde farklılık göstermiştir. Ortaçağda Avrupa'da ruhban sınıfını geliştirmeyi amaçlayan üniversiteler, 19. yüzyıl başlarında merkezi otoritenin ideolojisi doğrultusunda elit kadrolar yetiştirmeyi amaçlamıştır (Köksoy, 1997). Modern üniversite anlayışının gelişmesindeki en büyük rolü Berlin üniversitesinin kurucusu Wilhelm von Humbolt oynamış ve yükseköğretimde "Humbolt Modeli"ni uygulamaya koymuştur. Bu modele göre, üniversitenin görevi "bilim için bilim" yapmak, belli bir mesleğe yönelmeksizin araştırma ve eğitim öğretim yapmak ve bilgi üretmektir.

İkinci Dünya Savaşı'na kadar olan dönemde Batı Ülkeleri’ndeki çağdaş üniversite modellerinin şekillenmesinde Fransa'nın Napolyonik, İngiltere'nin Newmanian, Almanya'nın Humboltian üniversite modellerinin karş11ıklı etkileşimleri büyük rol oynamıştır (Kısakürek, 1976).

Yirminci yüzyılın ikinci yarısından itibaren dünyada politik gündemde güven ve sorumluluk kavramlarına vurgunun artması, üniversitenin merkezi olmayan bir yapıya geçmesine ve daha fazla sorumluluk almasına neden olmuştur. Merkeziyetçilikten uzaklaşma, amaçlarla yönetim, yerel yönetimlerin yetkilerinin artması, değerlendirme ve sorumluluk bu yeni oluşumun gerekleri olarak ortaya çıkmıştır. $\mathrm{Bu}$ yeni dünya düzeninin gereklerine uygun olarak birçok ülkede "yükseköğretimde kalite" konusu tartışılmaya başlanmıştır.

Power (1999) 1980'den itibaren denetim toplumunun gelişmeye başladığını belirtir. OECD ülkeleri 1980'de farklı düzeylerde bu denetimi oluşturma yoluna gitmişlerdir ve bu hareketi "Yeni Kamu Yönetimi" olarak adlandırılmışlardır (Hood, 1991). Bu reformun temel bileşenleri, öz denetim, otonomi ve ürün değerlendirme temeline dayalı bir mali destek sistemidir. Artan öz denetim ve otonominin sonucu olarak hükümetler üniversitelerin ve fakültelerin değerlendirilmesi ve akreditasyonu yoluna gitme kararı almışlardır.

Kalite güvencesi, bir yükseköğretim kurumu ya da programının önceden belirlenmiş ölçütlere göre sürekli değerlendirilmesidir (UNESCOCEPES, 2004) ve temelde kurum ya da programın nitelikli eğitim verebilmesi amacıyla yürütülmektedir. Kalite güvencesini sağlamak için kullanılan yöntemlerden birisi akreditasyondur. Akreditasyon, önceden belirlenen standartlara uygunluk açısından kurum ya da programın değerlendirilmesidir (Oakes, 1999). Bir diğer tanıma göre akreditasyon, kurumun kalitesinin sürekli bir değerlendirme ile onaylanması sürecidir (CRE,2001). CHEA (2000), akreditasyonu yükseköğretim programları ve üniversitelerde kalitenin geliştirilmesine yönelik dışsal değerlendirme süreci olarak tanımlar. 
Eğitimde kalite güvencesini sağlamada akreditasyon dışındaki diğer yöntemler değerlendirme, denetleme ve kyyaslamadır (Durman, 2007). Bu yöntemlerden bir ya da birkaçını kullanarak kurum ya da programın daha nitelikli eğitim vermesi sağlanabilir. Kalite güvencesi çalışmaları, kurum, program ya da konu alanı için yapılabilmektedir. Avrupa Yükseköğretim Kalite Güvence Birliği (ENQA) raporunda (2001) akreditasyon sürecinin değerlendirme süreçlerini içermekle birlikte; değerlendirmenin akreditasyon yerine geçemeyeceği belirtilmektedir. Ayrıca akreditasyonun değerlendirmeden farklı olarak kabul ya da red gibi daha sınırlı bir amacinın olduğu ve değerlendirmenin genellikle daha geniş amaçları içeren kapsamlı bir süreç olduğu belirtilmiştir. Akreditasyonda bir standartlar dizgesi söz konusu iken; değerlendirme sürecinin bir kısmında standartlara yer verilebilir ya da değerlendirmede standartlara hiç yer verilmeyebilir. Kalite güvencesini sağlamada kullanılan bir diğer yöntem "kıyaslama" (benchmarking)'dir (Danish Evaluation Institute, 2003). Akreditasyonda programın yerine getirmiş olması beklenen minimum standartlar belirlenirken, kıyaslama sürecinde mükemmellik ölçütleri yani en iyi örnekler esas alınmaktadır (Danish Evaluation Institute, 2003). Kiyaslamada herhangi bir dışsal ölçüte gerek olmaksızın süreç işletilebilir ve burada iyi örnekler söz konusudur (Kendall, 2001).

Kalite güvencesini sağlamada akreditasyon bir araçken; amaç, sürdürülebilir sürekli kalite iyileştirme olmalıdır (Atalay, 2006).

Türkiye'de Yükseköğretimde Akreditasyon Konusundaki Gelişmeler

Türkiye'de "Kalite Güvencesinde Avrupa İşbirliğinin Teşviki" kapsamında üniversiteler ve programlar 90'lı yıllardan itibaren değişik yerli yabanc1 kurumsal değerlendirme ve akreditasyon deneyimlerinden geçmişlerdir (UA, 2005). Türkiye'deki akreditasyon çalışmaları, mühendislik fakültelerinin, uluslararası mühendislik eğitimi kurumu olan ABET (Accreditation Board for Engineering and Technology) tarafindan akredite edilmeleri ile başlamıştır. 1994- 2004 yılları arasında Dört üniversitede (ODTÜ, Boğaziçi, Bilkent, İTÜ) toplam 33 mühendislik programı ABET eşdeğerlik belgesi almıştır. ABET'le ilişkiler sonrasında, 90'lı yılların sonunda, mühendislik programlarının ulusal akreditasyonu amacıyla, Mühendislik Eğitim Programları Değerlendirme ve Akreditasyon Derneği (MÜDEK) oluşmuştur. Bugün Mühendislik Avrupa Akreditasyon Programı (EUR-ACE) içinde yer alan MÜDEK, 2007 yılına kadar 14 farklı disiplinde 44 mühendislik lisans programını değerlendirmiştir (MÜDEK, 2007).

Türkiye'de değişik yükseköğretim kurumlarında Avrupa Üniversiteler Birliği (EUA)'nin Kurumsal Değerlendirme Programı uygulanmıştır. Çeşitli üniversite hastanelerinde uluslararası akreditasyon süreçleri başlatılmıştır. 
1994-98 yılları arasında Dünya Bankası finansmanı ile YÖK- Dünya Bankası işbirliği ile "Milli Eğitimi Geliştirme Projesi"” yürütülmüş ve ilk defa öğretmen eğitiminde standartlar ve akreditasyon belirleme çalışması yapılmıştır. YÖK, 1997'de, Ankara İngiliz Büyükelçiliği ve Unitas ile işbirliği içerisinde "Türk Üniversiteleri Kalite Değerlendirme Projesi” adlı pilot proje gerçekleştirmiştir.

2002-2003 tarihleri arasında Türkiye'deki üç üniversite EUA'nın “Kalite Kültürü Projesi”’ne katılmıştır. Programın 2005 dönemine katılmak üzere Türkiye'den iki üniversite seçilmiştir. Stratejik Planlama, Kurumsal Değerlendirme ve Akreditasyon çalışmaları farklı üniversitelerde yaygınlaşmıştır. MÜDEK'le birlikte Ulusal Kalite Güvencesi ve Akreditasyon Sistemi kurma çalışmaları hız kazanmıştır. Son olarak YÖK, "Yükseköğretim Kurumlarında Akademik Değerlendirme ve Kalite Geliştirme Yönetmeliği” hazırlamıştır.

"Yükseköğretim Kurumlarında Akademik Değerlendirme ve Kalite Geliştirme Yönetmeliği”, 25942 Sayı ve 20.09.2005 tarihli Resmi Gazetede yayımlanarak yürürlüğe girmiştir. Yönetmeliğin birinci maddesinde yönetmeliğin amac1 “..yükseköğretim kurumlarının eğitim, öğretim ve araştırma faaliyetleri ile idari hizmetlerinin değerlendirilmesi, kalitelerinin geliştirilmesi, bağımsız "dış değerlendirme" süreciyle kalite düzeylerinin onaylanması ve tanınması konusundaki çalışmalara ilişkin esasları düzenlemek" olarak belirtilmiştir. Bu yönetmelikle YÖK içerisinde Yükseköğretim Akademik Değerlendirme ve Kalite Geliştirme Komisyonu (YÖDEK) oluşturulmuş ve üyeler belirlenmiştir (YÖK, 2005). Mayıs 2006'da basılan "Yükseköğretim Kurumlarında Akademik Değerlendirme ve Kalite Geliştirme Rehberi" "3 ile YÖDEK, kalite geliştirme ve akademik değerlendirme raporlarının oluşturulmasında üniversitelere rehber olabilecek bir doküman ortaya koymuştur. Bu tarihten itibaren üniversitelerde öz değerlendirme süreçleri daha etkin işletilmeye başlanmıştır.

YÖK'deki akreditasyon çalışmalarının başlangıcını anlayabilmek için öncelikle çeşitli ülkelerdeki yükseköğretimde akreditasyon çalışmalarına bakmak gerekir. $\mathrm{Bu}$ araştırmanın amacı, yükseköğretimde akreditasyon konusunda deneyimli ülkeler olan İngiltere, Amerika Birleşik Devletleri ve Japonya'da akreditasyon süreçlerinin incelenmesidir. Aşağıdaki araştırma sorularına yanıt aranmıştır:

- İngiltere'de yükseköğretimde akreditasyon nasıldır?

- ABD'de yükseköğretimde akreditasyon nasıldır?

- Japonya'da yükseköğretimde akreditasyon nasıldır?

${ }^{3}$ http://www.yodek.org.tr/?page=download\# 


\section{YÖNTEM}

Araştırma betimsel nitelikli bir çalışma olup genel araştırma modelleri açısından varolan durumu, var olduğu şekilde betimlemeyi amaçlayan tarama modelidir (Karasar, 1998, s. 77).

Araştırmada, son yıllarda Türk yükseköğretiminde de sıkça duyulmaya başlanan "akreditasyon" konusu Türkiye' deki gelişmeler ve bazı ülkelerdeki gelişmeler açısından ele alınmıştır. Ülkelerin akreditasyon süreçleri, akreditasyonun yürütüldüğü kurum/ kurumlar ele alınarak incelenmiş ve ilgili ülkedeki akreditasyon işleyişi hakkında genel bilgiler verilmiştir.

Yükseköğretimde akreditasyon süreçleri incelenen ülkeler hakkındaki bilgilere web yoluyla ulaşılmıştır. Bazı ülkelerdeki dokümanlar akreditasyon kurumlarından posta yoluyla istenmiştir.

\section{BULGULAR}

İngiltere, Amerika Birleşik Devletleri ve Japonya'daki yükseköğretimin akreditasyonu süreçleri ayrı ayrı ele alınacaktır.

\section{İngiltere'de Yükseköğretimde Akreditasyon}

2000'li y1llara gelinceye kadar İngiltere' de yükseköğretimde bağımsız bir kalite güvencesi sistemi vard. Kalite güvencesi sistemi devlet denetimi ile özel kurumlar tarafından yürütülmekteydi. Bu sistem karmaşık olmakla birlikte etkili bir kalite güvence sistemidir. İngiltere'de yükseköğretimde amaçtan çok öğrenme ürünleri yaklaşımı benimsenmektedir (Armstrong, 2000).

2002'de Yükseköğretimde Kalite Güvencesi Ajansı (QAA) tarafından yeni bir model önerildi ${ }^{4}$. Bu modelde daha çok kurumların denetimini esas alan bir yapı söz konusu idi ve öz değerlendirme ve program belirteçleri ${ }^{5}$ vurgulandi.

İngiltere'de üniversiteler, verdikleri derecelerin kalitesi ve akademik standartlarından sorumludurlar. Yükseköğretimde Kalite Güvencesi Ajansı (QAA) ise üniversitelerin bu sorumluluklarını ne kadar iyi yerine getirdiğini denetlemekle sorumludur (QAA, 2005).

Yükseköğretimde kalitenin sağlanması amacıyla şu dört kalite prensibi uygulanmaktadır: üniversite otonomisi, toplam değerlendirme yerine

biçimlendirici değerlendirme süreçlerinin uygulanması, sayısal göstergelerden çok nitel çalışmalara yer verilmesi, üniversitelerin mezun

\footnotetext{
${ }^{4}$ http://www.ukcle.ac.uk/resources/quality/england.html

5 Programme specifications
} 
sayılarından çok mezunların niteliklerine yani süreçte neler kazanıldığına önem verilmesi.

QAA'nın amac1 yükseköğretimde kalitenin artırılması ve bunun için yükseköğretimde öğrenci, öğretim elemanı ve kurumun ihtiyaçları ve gelişmelere ilişkin halkı bilgilendirmektir (Anderson, Johnson, Milligan, 2000). QAA kurumsal denetim yapar ve sonuçları yayınlar. Ayrıca, nitelikler çerçevesinin geliştirilmesi, konu alanı standartları ve kıyaslama ölçütlerinin belirlenmesi, dış denetçilerin görevlerinin kapsamının belirlenmesi, uygulama yönergelerinin geliştirilmesi gibi görevler QAA'nın sorumluluğundadır.

QAA'nın görevi yükseköğretimin standartları ve kalitesine ilişkin toplumda güven oluşturmaktır. Yükseköğretim düzeyinde derslerin tanınmasına ilişkin sürecin nasıl olacağını da belirleyerek üniversitelere verilecek destek konusunda hükümete görüș bildirir. Öğrenci, ișveren ve üniversitelere karşı devletin sorumluluklarını yerine getirir ve düzenli olarak raporlar yayınlar (QAA, 2005).

QAA "kurumsal kalite denetimi" ve "program akreditasyonu" yapmaktadır. Kalite güvencesini sağlamada yararlanılan bu iki sürecin kısaca açıklanmasında yarar vardır.

\section{Kurumsal Kalite Denetimi}

Kurumsal kalite denetiminin amacı, kurumun geleceğini güvence altına almak için gelişmeye açık olası alanların belirlenmesi ve kalitenin güvence altına alınmasıdır. QAA'da denetim şu dört konu üzerinde odaklanmaktadır: kurumun kalite stratejisi, öğrenme altyapısı, akademik standartlar ve iletişim. "Kurumun kalite stratejisi" içerisinde kurumun stratejik planlama ve gözden geçirme süreci, karar verme süreci, programların işleyişi ve gözden geçirilmesi sürecindeki düzenlemeler, öğretim ve araştırma süreçlerine ilişkin kalite stratejileri, kalite geliştirme ve iyi örneklerin yayınlanması ele alınır.

“Akademik standartlar" akademik standartların belirlenmesi, bu süreçte dış denetçilerin rolü, standartların uygulanmasındaki diğer araçlar ve lisansüstü eğitim sürecindeki standartlar üzerine yoğunlaşır.

"Öğrenme altyapısı" akademik personel ve bu personelin süreç içerisindeki eğitimleri, ödül ve destekleri ayrıca öğrenci desteği ve rehberliği incelenir. incelenir.

"İç dış iletişim" içerisinde de iyi örneklerden nasıl yararlanıldığı 


\section{Program Akreditasyonu}

İngiltere'de programların akreditasyonu QAA'dan önce Yükseköğretimin Finansmanı Konseyi (HEFCE) tarafından yapılmaktaydı (Brumfitt, 2003). Şu anda program akreditasyonu QAA içerisinde "Program İnceleme Direktörlügü̈” tarafından yürütülmektedir.

Program akreditasyonu sürecinde kurumun eğitsel yetkinliği iki aşamalı bir süreçle incelenmektedir: öz değerlendirme ve dışsal meslektaş değerlendirmesi ${ }^{6}$. İngiltere' de konu alanı standartlarının uygulanmaya başlandığı 1992 y1lından bu yana uygulama ile ilgili çok fazla değişiklikler yapılmıştır. İlk zamanlarda programlar üçlü derecelendirme sistemi ile çok iyi, yeterli, yetersiz olarak değerlendirilirken ve alan ziyareti yapılmazken; 1995'den itibaren programlar belirlenen altı alt başlık altında dörtlü derecelendirme sistemi üzerinden değerlendirilmektedir (QAA,2005). Programlar şu altı alt başlık altında değerlendirmeye alınmaktadır:

- Program deseni, içeriği ve organizasyonu

- Öğretim, öğrenme ve değerlendirme

- Öğrenci başarısı ve gelişimi

- Öğrenci desteği ve yönlendirme

- Öğrenme kaynakları

- Kalite güvencesi ve iyileştirme

Programin belirtilen bu altı alandan birinde dörtlü derecelendirme üzerinden bir alması durumunda program akreditasyonu yapılamaz ve sonraki 12 ay içerisinde bir ek ziyaret gerçekleştirilir. Bu altı alandan üç ya da daha fazlasında iki puan alınması da problemli bir durum olarak ele alınır ve bu durumda kurumun gelişim planı hazırlayarak sunması istenir. Her bir konu alanı ziyaretinin ardından QAA sonuç raporunu yayınlar.

QAA içerisinde dış denetim de önemli bir yere sahiptir. İngiltere'de lisans programları, mezuniyet sonrası araştırma programları ve öğretmen eğitimi programları için dış denetim yapılmaktadır (QAA, 2005). Lisans programları ve mezuniyet sonrası araştırma programlarının dış denetimi HEFCE tarafindan yapılırken, öğretmen eğitimi programları Okul Eğitim ve Gelişim Ajansı (TDA) (TTA) $^{7}$ ve Eğitim Standartları Ofisi (Ofsted) ${ }^{8}$ tarafından dış denetime tabi olmaktadırlar.

\footnotetext{
${ }^{6}$ Peer review

${ }^{7}$ Eski adıyla TTA - Teacher Training Agency yeni adı TDA - Training and Development Agency for Schools (TDA) yeni hali

${ }^{8}$ Ofsted - Office for Standards in Education
} 
QAA'da dış denetim sisteminde, öz değerlendirme, meslektaş değerlendirmesi ve sonuçların yayınlanması söz konusudur.

Öz değerlendirme: Her üniversite ya da kurum öncelikle bir öz değerlendirme raporu hazırlar. Bu rapor, kurumun iç değerlendirmesi niteliğinde olup güçlü zayıf yönlerin ortaya konulduğu ve gelişmeye ihtiyaç duyulan alanların belirtildiği bir rapordur. Bu rapor ziyaret ekibinin temel referans belgesi niteliğindedir.

Meslektaş değerlendirmesi: Aynı konu alanında çalışan öğretim üyelerinden oluşan bir grup değerlendirmeye katılır. Bu ekibe seçilebilmek için gerekli ölçütler QAA tarafından yayımlanır. Bu ekibe katılan tüm görevliler alan ziyaretinden önce bir eğitime tabi tutulurlar.

Ziyaret öncesi hazırlık aşamast: Kurum akreditasyon ziyaretinden en az altı ay önce bilgilendirilir ve ziyaret planı çıkarılır. QAA her bir ziyaret için 4-6 kişiden oluşan bir ziyaret ekibi oluşturur ve bu ekip alan ziyaretinden önce kurumun verdiği bilgiler ışığında kağıt üzerinde değerlendirme yapar.

Alan ziyareti: Alan ziyareti ziyaret edilen kuruma ve değerlendirme sürecinin türüne göre değişir. Alan ziyareti sırasında öğrenciler ve çalışanlarla görüşmeler düzenlenir. Ekiptekiler kurumun öz değerlendirme raporunda belirttiklerini yerine getirip getirmediklerini test ederler. Ekip ayrica ziyaret sırasında kurumun akademik altyapısını da inceler.

Sonuçların yayınlanması: Uzmanların yaptıkları alan ziyaretlerinin sonuçları yayınlanır.

Dış denetim sürecinde, dış denetmen ${ }^{9}$ ile akademik denetmenin ${ }^{10}$ görevleri farklılaşmaktadır. Dış denetmenin görevi bir bölümdeki öğrenci performansını ilgili bölümün standartları açısından değerlendirmek ve değerlendirmenin geçerli ve adil olarak yapılmasını sağlamaktır. Akademik denetmen ise kurumu her altı yılda bir ziyaret eder ve daha geniş bir bakış açısı ile üniversite standartlarının uygunluğunu gözden geçirir. Akademik denetmenin belli bir programın standartlarına ilişkin söz hakkı vardır; ancak bireysel olarak öğrenci performansı ile ilgili herhangi bir şey yapmazlar. Akademik denetmenlerin kurumun diş denetmenlere ve uygulama yönergelerine ilişkin süreçleri işletişlerini eleştirme ve bu konularda görüş bildirme hakları vardır.

İngiltere'de yükseköğretime kalite güvencesini sağlama sürecinin akreditasyondan çok denetim olduğu söylenebilir.

\footnotetext{
9 external examiner

${ }^{10}$ academic reviwer
} 


\section{Amerika Birleşik Devletleri’nde (ABD) Yükseköğretimde Akreditasyon}

Akreditasyon ilk olarak, yirminci yüzyılın başlarında Amerikan eğitim sisteminde ortaya çıkmıştır. ABD'de akreditasyon kurumları yükseköğretimdeki artış ve yeni çalışma alanlarının ortaya çıkmasının sonucu olarak gelişmiştir. ABD'de ilk bölgesel akreditasyon ajansı 1885'de kurulmuş, ilk akreditasyon 1910'da yapılmıştır (K1sakürek, 2007). İlk ihtisaslaşmış akreditasyon ajansı 1907'de tıp alanında açılmıştır. ABD'de yükseköğretimde akredite edilen kurum ya da program sayıları her geçen gün artmakta ve akreditasyon kurumları sürekli olarak değişmektedir.

ABD'de üç tür akreditasyon yapısından söz etmek mümkündür:

Bölgesel Akreditasyon Kurumlarl: Devlet, özel, kar amacı güden ya da gütmeyen, iki ve dört yıllık yükseköğretim kurumlarını akredite ederler. ABD'de altı adet bölgesel akreditasyon kurumu vardır. Bunlar: New England Association of Schools and Colleges (NEASC), North Central Association of Schools and Colleges (NCA), Middle States Association of Schools and Colleges (MSA), Southern Association of Schools and Colleges (SACS), Western Association of Schools and Colleges (WASC), Northwest Association of Schools and Colleges (NWCCU)'dir. Bölgesel akreditasyonda tüm kurumsal etkinliklerin kapsamlı bir gözden geçirilmesi söz konusudur.

Ulusal Akreditasyon Kurumlarl: Burada genellikle tek bir amaca yönelik kurumlar, uzaktan eğitim veren kolej ve üniversiteler ile dini temelli vakıf okullarının akreditasyonu söz konusudur.

Mesleki (Uzmanlaşmış) Akreditasyon Kurumları: Tek bir programın akreditasyonundan sorumlu kurumlardır.

ABD' de akreditasyon süreci bir-iki yıldan on yıla kadar değişebilen bir süre için söz konusudur. Kurumun ön kabul alması akredite edildiği anlamına gelmez. Akreditasyon sürecinde şu beş konu önemlidir:

1- Öz değerlendirme: Kurum ya da programlar akreditasyon kurumunun belirlediği standartlar çerçevesinde bir öz değerlendirme raporu oluştururlar.

2- Meslektaş değerlendirmesi: Kurum ya da programın akreditasyona uygunluğu öncelikle alandaki yöneticiler ve meslektaşlar tarafindan değerlendirilir. Burada aynı meslek grubundan kişiler öz değerlendirme raporlarını ve program/ kurumu değerlendirirler.

3- Alan ziyareti: Akreditasyon kurumu program ya da kurumun akreditasyonu için oluşturduğu bir ekibi gözlem yapmak üzere kuruma gönderir. Burada ziyaretin ayrıntılarını kurumun öz değerlendirme 
raporu belirler. $\mathrm{Bu}$ ziyaret ekibinde, alan uzmanlarının yanında yükseköğretimle ilgili akademisyen olmayan kişiler de yer alabilir. Ekip üyeleri gönüllüler arasından seçilir ve genellikle bir ücret ödenmez.

4- Akreditasyon kurumunun değerlendirmesi: Akreditasyon kurumu program ya da kurumun akreditasyonuna, akredite olabilmek için gerekli bazı düzeltmeleri yapmasina ya da akreditasyonunun reddine karar verebilir.

5- Gözden geçirmenin sürekliliği: Program ya da kurum belli aralıklarla akreditasyona uygunluk açısından değerlendirilir. Her değerlendirme sürecinde öz değerlendirme raporlarının belirlenen standartlar çerçevesinde tekrar hazırlanması gerekmektedir.

\section{ABD'de Akreditasyon Kurumlarının Tanınması}

ABD'de akreditasyon, kar amacı gütmeyen bağımsız kurumlar tarafından yürütülmektedir. $\mathrm{Bu}$ kurumların yürüttükleri akreditasyon süreçlerinin tanınması için, kurumlar dış değerlendirmeye tabi tutulurlar ve belli aralıklarla öz değerlendirme yaparlar. Akreditasyon kurumlarının tanınması Yükseköğretimde Akreditasyon Konseyi (CHEA) ${ }^{11}$ gibi başka bir özel kurum ya da Amerika Birleşik Devletleri Eğitim Bakanlığı (USDE) ${ }^{12}$ tarafından gerçekleştirilir. Akreditasyon süreci devlete bağlı olmamasına rağmen, akreditasyon kurumlarının tanınması devletin sorumluluğundadır. CHEA akreditasyon kurumlarının tanınmasına ilişkin beş standart ortaya koymuştur. CHEA tarafindan tanınan akreditasyon kurumlarının on yıllık sürelerle tekrar akredite edilirler ancak beş y1lda bir de kurum ya da programın ara rapor hazırlaması istenir. Değerlendirme, CHEA tarafindan oluşturulan ve kurum temsilcileri, akreditasyon kurumları ve kamu temsilcilerinden oluşan "Tanınma Komitesi” tarafından yapılır. Komite öz değerlendirme raporuna göre akreditasyon kurumunu gözden geçirir ve gerekli görürse alan ziyareti yaparak kurumun tanınmasına ilişkin bir karara varır. Komite incelemeleri sonunda akreditasyon kurumunun "tanınması" ya da "tanınmaması" gerektiğine ilişkin CHEA' ya görüş bildirir.

ABD Eğitim Bakanlığı standartları ise kurum ya da programın kalitesi üzerine odaklanmaktadır. USDE, kurum ya da programın federal fondan, öğrenci yardım fonlarından ya da diğer federal programlardan yararlanabilmesi için yeterli düzeyde kaliteye sahip olup olmadığını değerlendirir. USDE, akreditasyon kurumunun öğrenci başarısı, programlar, fakülte, olanaklar, mali ve idari kapasite, öğrenciye sunulan olanaklar gibi belli alanlarda belirlediği standartları ne kadar karşılayabildiğini ortaya

${ }^{11}$ The Council for Higher Education Accreditation - CHEA

${ }^{12}$ United States Department of Education - USDE 
koyar. Akreditasyon kurumunun USDE tarafından tanınması beş yıl süreyle geçerli olur. USDE çalışanları tanınma sürecinde akreditasyon kurumunun yazılı raporu ve alan ziyaretlerinden yararlanır.

ABD'de birçok akreditasyon kurumu USDE ve CHEA tarafından tanınmaktadır, ancak bu iki kurumdan tanınma sağlamayan akreditasyon kurumları da vardır. Akreditasyon kurumlarının USDE ya da CHEA tarafından tanınırlık almak istemelerinin nedenleri şöyle sıralanmaktadır (Eaton, 2005); USDE tarafindan tanınırlık alınması kurumlar ya da programların federal öğrenci fonundan yararlanabilmesini sağlamaktadır. CHEA tarafindan tanınma da akreditasyon kurumları arasında akademik meşruluk sağlayarak program ya da kurumun ulusal yükseköğretim kurumları arasında saygınlığını artırmaktadır.

\section{Japonya'da Yükseköğretimde Akreditasyon}

Japonya'da üniversiteler her yedi y1lda bir değerlendirilmeye tabi tutulmaktadır. Bu değerlendirmeyi Eğitim, Kültür, Bilim ve Teknoloji Bakanlığ 1 (MEXT) tarafından akredite edilmiş bir değerlendirme kurumu yapar. NIAD-UE ${ }^{13}$ gibi bazı özerk kurumlar da bu değerlendirmeyi yapabilmektedir. Üniversiteler kendilerini değerlendirecek olan akreditasyon kurumunu kendileri seçerler (NIAD-UE, 2005).

Japonya'da 1996'da üniversite akreditasyonunda yeni bir sistem uygulanmaya başlamıştır. Bu sistem akreditasyona başvuran üniversitenin öz değerlendirmesini gerektiren bir sistemdir. 1996'dan beri 300 üniversite akredite edilmiştir (JUAA, 2006).

Japonya'da yükseköğretimde 2000 yılından önceki kalite kontrol sistemi şu dört ana konuda toplanabilir (Akiyoshi, Y., 2002)

- Japon Üniversite Akreditasyon Birliği (JUAA) tarafindan akreditasyon

- Kurumların ayrı ayrı öz değerlendirme yapması

- Farklı mesleki kurumlar tarafindan yapılan akreditasyon

- Devlet tarafindan onay, denetim.

Japon Üniversite Akreditasyon Birliği (JUAA) Tarafindan Akreditasyon

Japon Üniversite Akreditasyon Birliği II. Dünya Savaşı'ndan hemen sonra Amerika'daki bölgesel akreditasyon kurumları örnek alınarak kurulmuştur. Başlangıçta JUAA Amerikan bölgesel akreditasyon

${ }^{13}$ National Institution for Academic Degrees and University Evaluation 
kurumlarından farklı olarak çalışmış ve birlik yetkilileri eğitim bakanlığına bağlı olarak akreditasyon yapmıştır. Ancak Eğitim ve Bilim Bakanlığı'nın 1956 'da kendisinin de akreditasyon yetkisini alması ile JUAA kendisine üye üniversitelere gönüllü akreditasyon yapan bir kurum olmuştur (Baba ve Hayata, 1997; Shimizu, Baba ve Shimada, 2000) .

Amerikan bölgesel akreditasyon kurumlarından farklı olarak JUAA tarafindan akredite edilmek üniversitelerin işleyişi için zorunlu olan bir süreç değildir. Japonya'da Amerika'dan farklı olarak tüm üniversiteler Eğitim ve Bilim Bakanlığına bağlı olduğu için JUAA'ya üye olmayan kurumlar da öğrenci fonlarından yararlanabilmektedirler. Amerika'da öğrenci fonlarından yararlanabilmek kurumun akreditasyonunu gerektirir. Japonya'da kurumların akreditasyon almış olması statü göstergesi olarak algılandığı için üniversitelerin ancak üçte biri JUAA'ya tam üyedir (Akiyoshi, 2002).

Japon Üniversite Akreditasyon Birliği’ne dört yıllık lisans eğitimi veren üniversiteler üye olabilir. Birlik iki tür akreditasyon yapmaktadır. Birincisi başlangıç akreditasyonu niteliğindedir ve başvuran üniversitenin birliğe tam üyelik istediği durumda yapılır. Tekrar akreditasyon değerlendirmesi ise tam üye statüsündeki kurumlar için düzenli olarak yapılır. Devlet ya da özel statüdeki tüm üniversiteler JUAA'ya akreditasyon için başvurabilir. Üniversite JUAA tarafından başarılı bir şekilde akredite edildiği zaman kurum nitelikli eğitim verebilen kurum olarak sertifika alır.

JUAA "da akreditasyon, "Akreditasyon Komitesi" ve onun alt komisyonları tarafindan yürütülür. "Tekrar akreditasyon" ise "Tekrar Akreditasyon Komitesi" ve onun alt komisyonlarının sorumluluğundadır. Akreditasyon sürecindeki en önemli oluşumlar akreditasyon ve tekrar akreditasyon komiteleridir. $\mathrm{Bu}$ iki komite akreditasyon ve tekrar akreditasyona ilişkin kararları vermekle yükümlüdür. Ancak birliğin sonuç kararı mütevelli heyeti ve danışma kurulunun kararına bağlıdır. Akreditasyon ve tekrar akreditasyon komitelerine seçilecek üyeler de bu danışma kurulunun oyları ile belirlenir.

Akreditasyon süreci kısaca şu şekilde işlemektedir: Akreditasyona başvuran kurum JUAA tarafından hazırlanan ölçütlere uygun olarak öz değerlendirme raporunu hazırlar. Hazırlanan bu raporu JUAA'ya verir. JUAA içerisindeki daimi görevli komite bu öz-değerlendirme raporunu değerlendirir. Alan ziyareti gerçekleştirilir. Alan ziyareti sonuçları da dikkate alınarak başvuran kurum hakkında değerlendirme raporu hazırlanır. $\mathrm{Bu}$ hazırlanan rapor hakkında başvuran kurumun görüşleri de alındıktan sonra son hali verilir. Daha sonra kesin sonuç yayınlanır.

JUAA'da akreditasyonunun amac1, üniversitelerin sürekli gelişimini desteklemek ve değerlendirilen üniversitelerdeki kaliteyi garanti altına almak olarak belirtilmektedir. 
Akreditasyon sürecindeki değerlendirme şu dört özelliğe sahiptir (JUAA, 2006):

- Başarı düzeyi ve standart temelli değerlendirme. JUAA başarı düzeyine göre değerlendirmeye büyük önem vermektedir. JUAA üniversitelerin misyon, genel amaç ve eğitsel hedeflerine ne düzeyde ulaşabildiğini değerlendirir. Ayrıca standartlara dayalı bir değerlendirme de yapar. Burada da akredite edilecek kurumun "eğitim" ve "araştırma" konularında belirlenen standartlara ne kadar ulaşabildiği değerlendirilir.

- Üniversitenin bir bütün olarak ve konu alanlarının değerlendirildiği kapsamlı değerlendirmeler. JUAA üniversiteleri değerlendirmek için "Konu Alanı Ders İnceleme Alt Komitesi" oluşturur. Bu alt komite lisans ve lisansüstü düzeyde eğitim programlarını, öğretimi ve araştırma olanaklarını inceler. JUAA içerisindeki bir diğer alt komite de "Kurumsal İnceleme Alt Komitesidir". $\mathrm{Bu}$ alt komite de üniversitedeki eğitim ve araştırma olanaklarını, araç-gereç ve olanakları, kütüphane olanaklarını, sosyal olanakları, öğrenci servisini, yönetim ve çalışanları bir bütün olarak inceler. "Finansal İnceleme Alt Komitesi" ise üniversitenin finansal etkinliklerini inceler. Tüm bu üç alt komitenin çalışmalarının sonucu üniversite hakkında ayrıntılı ve kapsamlı bir rapor oluşturulur. Küçük üniversitelerin değerlendirme süreçlerinde de "Üniversite İnceleme Alt Komitesi" oluşturulur. Bu komite "Kurumsal İnceleme Alt Komitesi" ile "Konu Alanı İnceleme Alt Komitesi" birleştirilmiş halidir.

- Üniversitelerin sürekli gelişimi için tekrar akreditasyon. JUAA tarafından akredite edilip tam üyelik hakkı kazanan üniversiteler beş yıl sonra ilk tekrar akreditasyona başvururlar. Daha sonraki her yedi y1lda da kurum tekrar akreditasyona başvurmak zorundadır. İlk tekrar akreditasyon sonrasındaki gelişimin tekrar akreditasyondan üç yıl sonra rapor edilmesi istenir.

- Meslektaş değerlendirmesi. JUAA değerlendirmecileri genellikle tam üyelik hakkı kazanan üniversitelerdeki fakülte üyeleri arasından seçilmektedir.

\section{Kurumların Ayrı Ayrı Öz Değerlendirme Yapması}

1991'de Japon hükümeti üniversitelerin kuruluşunda belli standartların uygulanmasını kararlaştırmıştır. Ayrıca üniversite eğitiminin kalitesinin artırılması için üniversite konseyi öz değerlendirme yapılması kararı almıştır (Kitamura, 1997). Ancak 1991'deki bu raporda akademik özgürlüklerin kısıtlanabileceği düşüncesi ile dış değerlendirmeden söz edilmemiştir (Akiyoshi, 2002). 


\section{Farklı Mesleki Kurumlar Tarafindan Yapılan Akreditasyon}

Üniversitelerin öz değerlendirme yapmaya başlamaları Japonya'da üniversite yönetimi anlayışını değiştirmekle birlikte, 1980'den sonra Japon ekonomisindeki farklılaşma toplumun sosyal kimliğini de etkilemiştir (Akiyoshi, 2002). Ayrıca global standartların ve yükseköğretimde kalite güvencesi düşüncesinin daha fazla etkin olmasıyla birlikte mesleki akreditasyon kurumları ortaya çıkmıştır (Akiyoshi, 2002). 1999'da kurulan Japon Mühendislik Eğitiminin Akreditasyonu Kurumu JABEE ${ }^{14}$ bunun en iyi örneğidir. Amerika'daki ABET'in Japonya'daki eşdeğer kurumu olarak görülebilecek JABEE mühendislik eğitiminde uluslararası standartların uygulanmasinı hedefleyen bir kurumdur.

\section{Devlet Tarafindan Onay, Denetim}

Japonya yükseköğretim yasasına göre yükseköğretimin kalitesinden devlet sorumludur. Burada eğitimin kalitesinden sorumlu asıl kurum Eğitim ve Bilim Bakanlığı (MEXT)'dır. Bakanlık içerisindeki “Üniversite Kuruluş Konseyi" yeni oluşturulan üniversitelerin kalitesinden sorumludur ve bakanlık tarafından yönetilir. Ancak Japonya'da yükseköğretiminin akreditasyonu, Eğitim ve Bilim Bakanlığı tarafından düzenlenen dönemsel ziyaretler dışında temelde kurumların kendi çabalarına dayanmaktadır.

2000'li yıllara kadar yukarıda belirtilen dört grupta toplanan yükseköğretimde akreditasyon çalışmaları (Akiyoshi, 2002) 2000'li yıllardan sonra farklılaşmıştır. 1991'de "Akademik Dereceler Ulusal Kurumu” kısa adı ile NIAD ${ }^{15}$, toplumun değişen farklılaşan yükseköğretim ihtiyaçlarına karşı1ık verilebilmesi amacıyla devlet ve özel üniversitelerin desteğiyle kurulmuştur (NIAD-UE, 2007). NIAD akademik derecelerin verilmesinden sorumlu bağımsız bir kurumdur. 2000'de bu kurumun görevleri arasına üniversitelerin değerlendirilmesi de eklenmiş ve adı Akademik Dereceler ve Üniversite Değerlendirmesi Ulusal Kurumu NIAD Akademik Dereceler ve Üniversite Değerlendirme Ulusal Kurumu (NIAD-UE) olarak değiştirilmiş ve 2004'de bağımsız bir kurum olmuştur.

NIAD-UE akademik derecelerin tanınmasının yanında kalite güvencesi ile ilgili çalışmalar yürütmektedir. NIAD-UE devlet kurumlarından bağımsız olarak akademik değerlendirme yapan bir kurumdur. NIAD-UE'nin dört temel görevi vardır:

\footnotetext{
${ }^{14}$ Japan Accreditation Board for Engineering Education - JABEE

${ }^{15}$ National Institution for Academic Degrees
} 
- Üniversitelerin değerlendirilmesi,

- Üniversite değerlendirme sistemleri ve kalite geliştirme süreçleri hakkında araştırmalar yapılması,

- Değerlendirilme süreçlerinde elde edilen verilerin analizi ve sonuçların yayınlanması,

- Akademik derecelerin (lisans, yüksek lisans, doktora) verilmesi.

\section{Akademik Dereceler ve Üniversite Değerlendirme Ulusal Kurumu (NIAD-UE)}

NIAD-UE üniversitelerin kalite geliştirme süreçlerinin özerk bir süreçte yürütülmesi gerektiğini savunmaktadır. Her kurumun araştırma, sosyal olanaklar ve eğitimdeki hedeflerini belirlemesi beklenir. Değerlendirme programı üç türdür; tematik değerlendirme, akademik alanlardaki eğitsel etkinliklerin değerlendirilmesi, akademik alanlardaki araştırma etkinliklerinin değerlendirilmesi. Ayrıca devlet üniversitelerinin eğitsel ve araştırma alanlarındaki etkinliklerinin topluma duyurulması için NIAD'a yıllık rapor vermeleri gerekmektedir.

- Tematik değerlendirme: Tematik değerlendirme, tüm Japonya'daki üniversite sisteminin bütünü ile ilgili belli bir temaya dayalı olarak yapılan değerlendirmedir. Temalar eğitim, araştırma, yönetim, sosyal etkinlikler gibi üniversite etkinliklerinin farklı boyutları arasından seçilmelidir. Gözden geçirme ve değerlendirme uluslararası karşılaştırmaları da içeren farklı boyutlarda gerçekleştirilir.

- Akademik alanlardaki eğitsel etkinliklerin değerlendirilmesi: Akademik alanlardaki eğitsel etkilikler beş yıllık dönemlerle değerlendirilir. Değerlendirmede misyon ifadesi ana faktör olarak ele alınmaktadır. Konu alanı değerlendirmesinde şu boyutlar değerlendirilir: eğitimin amaçları; içerik ve öğretim yöntemi; öğrenci desteği, eğitsel ürünler, hedeflere ulaşma oranı; sosyal olanaklar, hizmetler, öğrenci değişim olanakları; eğitimin kalitesini artıracak, geliştirecek sistemler.

- Akademik alanlardaki araştırma etkinliklerinin değerlendirilmesi: Üniversitenin lisans, lisansüstü eğitim, enstitüler, araştırma merkezlerinde yürütülen araştırma etkinlikleri beş yıllık sürelerle değerlendirilirler. $\mathrm{Bu}$ değerlendirme sürecinde şu boyutlara bakılır: üniversitenin kuruluş amacı ve araştırmalarının hedefleri; araştırmaların içeriği ve düzeyi; araştırmaların topluma, ekonomiye ve kültüre katkıları; üniversitenin kuruluş amacına ne kadar ulaşabildiği; araştırmaların kalitesinin iyileştirilmesine yönelik sistemler. 
- Ulusal üniversitelerin yıllık değerlendirilmesi: Japonya'daki ulusal üniversiteler 2002-2003 akademik yılından bu yana NIAD tarafindan değerlendirilmeye tutulmaktadırlar. Bu değerlendirme sonuçları yıllık olarak NIAD tarafindan analiz edilip halka duyurulmaktadır.

NIAD-UE içerisinde üniversitelerin akreditasyonunu yapan alt komisyonlar ve derecelerin (lisans-lisansüstü) verilmesi ile ilgili bir komisyon yer almaktadır. Akreditasyona ilişkin şu alt komiteler yer almaktadir ${ }^{16}$ :

- Üniversiteler Akreditasyon Komitesi

- İki Yı1lık Meslek Yüksekokulları Akreditasyonu Komitesi

- Teknoloji Kolejleri Akreditasyon Komitesi

- Hukuk Fakülteleri Akreditasyon Komitesi

- Ulusal Üniversite Eğitim ve Araştırma Değerlendirme Komitesi

NIAD-UE akreditasyon sürecinde başvuran kurumlar NIAD'ın 11 standart alanına göre öz-değerlendirme yapar. Daha sonra NIAD-UE bu özdeğerlendirme sonuçlarını da dikkate alarak kurumu değerlendirir.

Değerlendirme esas olan 11 standart alanı şöyledir:

- Üniversitenin misyonu

- Eğitim ve araştırma olanakları

- Fakülte çalışanları ve araştırmacılar

- Öğrenci kabulü

- Eğitim programı

- Eğitimin başarısı

- Öğrenci servisleri

- Hizmetler, olanaklar

- Eğitimin kalitesini artıracak sistemler

- Finans

- Yönetim

\footnotetext{
${ }^{16}$ http://www.niad.ac.jp/index_e.html
} 


\section{SONUC VE ÖNERILER}

İncelenen ülke örneklerinden ve Türkiye'deki gelişmelerden yola çıkılarak yükseköğretimde akreditasyon konusunda şu sonuçlara ulaşılmıştır:

- Türkiye'de YÖK içerisindeki YÖDEK yapılanması ile birlikte üniversiteler içerisinde Akademik Değerlendirme ve Kalite Geliştirme (ADEK) kurulları oluşturulmuş ve öz değerlendirme çalışmaları daha sistematik bir şekilde yapılmaya başlanmıştır.

- Akreditasyon, yükseköğretim kurumları ve/veya programlarında kalite geliştirme, kurum ya da programa mali destek sağlanmas1, akademik arenada saygınlık kazanmak gibi nedenlerle yapılmaktadır. Akreditasyon mekanizmasının ülkedeki yerine ve işleyişine göre işlevi farklılaşmaktadır. Örneğin Amerikan yükseköğretimindeki bölgesel akreditasyon uygulamalarından farklı olarak Japonya'da JUAA tarafindan akredite edilmek üniversitelerin işleyişi için zorunlu olan bir süreç değildir. Amerika'da öğrenci fonlarından yararlanabilmek kurumun akreditasyonunu gerektirirken; Japonya'da Amerika'dan farkl1 olarak tüm üniversiteler Eğitim ve Bilim Bakanlığına bağlı olduğu için JUAA'ya üye olmayan kurumlar da öğrenci fonlarından yararlanabilmektedirler. Amerika'da akreditasyon daha çok finansal destekle ilişkilendirilmektedir.

- Akreditasyon genellikle bağımsı kurumlar tarafindan yapılmaktadır. Ancak bu kurumların da bağımsız ya da devlete bağlı kurumlar tarafindan tanınması ya da bir anlamda akreditasyonu yapılmaktadır. Amerika'da Amerikan Eğitim Bakanlığı (USDE) tarafindan tanınma öğrenci fonlarından yararlanmayı sağlarken, özel bir kurum olan Yükseköğretimde Akreditasyon Konseyi (CHEA) tarafından tanınma akademik statü göstergesi olarak görülmektedir.

- İngiltere'de akreditasyon diğer ülkelerden farklı olarak devlet tarafindan yürütülür. Yükseköğretimin akreditasyonu "Kalite Güvencesi Ajansı" (QAA) tarafından yapılır ve ayrıca üç alanda dış denetleme yapılır: lisans programlart, lisans sonrası araştırma programları, ögretmen eğitimi programları. Öğretmen eğitiminin dış denetimini "Okul Eğitim ve Gelişim Ajansı" (TDA) yapar. TDA da eğitim bakanlığına bağlı olarak çalışmaktadır. Ancak işleyişe bakıldığında sürecin akreditasyondan çok denetim mekanizması olduğu görülmüştür.

- Devlet tarafindan yapılan akreditasyon süreci daha çok programların yeni açılması durumunda programın onayı niteliğindedir. 


\section{Öneriler}

- Kalite güvencesi çalışmalarının devlet kurumları tarafından yapılması durumunda bu süreçlerin akreditasyon değil değerlendirme ya da denetim olarak adlandırılması gerekir. Akreditasyon ancak bir dış değerlendirme yapılması ve ölçütlerin bağımsız olarak belirlendiği durumlarda kullanılmalıdır.

- Türkiye'de akreditasyon çalışmalarının başlaması Türk üniversitelerinde "kalite" kavramının daha iyi anlaşılması açısından olumlu bir gelişme olmakla birlikte, problemlerin daha iyi tespit edilebilmesi için "dış değerlendirme" sistemlerinin sayısının artırılması önemlidir. Akreditasyon tanımlarına ve farklı ülkelerdeki uygulamalara bakıldığında akreditasyonun bir tür "dış değerlendirme" süreci olduğu görülmektedir. $\mathrm{Bu}$ dış değerlendirmenin üçüncü bir taraf tarafından yapılması gerekir. Bugüne kadar YÖK içerisinde yürütülen kalite güvencesi çalışmaları daha çok değerlendirme ya da denetim kapsamında ele alınabilir.

- Son yıllardaki ADEK uygulamaları kurumların ve programların "öz değerlendirme" süreçleri ile daha fazla tanışı olmalarını beraberinde getirmiştir. Türkiye'de akreditasyon sürecinin etkin kullanımı yükseköğretimde kaliteyi iyileştirmede önemli bir rol oynayabilir.

- Türkiye'de çeşitli programların akreditasyonunu yapacak mühendislik eğitimindeki MÜDEK benzeri oluşumlara ihtiyaç vardır.

\section{KAYNAKLAR}

Akiyoshi, Y. (2002). The new quality assurance system for Japanese higher education: Its social background, tasks and future. Web: http://svrrd2.niad.ac.jp/rue/n002/a00202.pdf adresinden 19-06-2007'de alınmıştır.

Anderson, D., Johnson, R., Milligan, B. (2000). Quality assurance and accreditation in Australian higher education: An assessment of Australian and international practice. The Australian National University: Center for Continuing Education.

Armstrong, P. (2000). Never mind the quality, measure the length: Issues for lifelong learning. supporting lifelong learning global colloquium. Web: http://www.open.ac.uk/lifelong-learning/papers/3937C6F7-0005-6542000015700000157_PaulArmstrongPaper.doc adresinden 12.10.2005'de alınmıştır. 
Atalay, S. ( 13 Kasım 2006). Kalite Güvencesi ve Akreditasyon. Bologna Sürecinin Türkiye'de Uygulanması Projesi Malatya İl Toplantısı'nda sunulmuş̧tur. İnönü Üniversitesi: Malatya. Web: http://abofisi.inonu.edu.tr/bolognasunumlar/Prof.\%20Dr.\%20Suheyda\% 20Atalay Kalite Guvencesi Akreditasyon-Malatya\%20kisa.ppt adresinden 27. 09.2007'de alınmıştır.

Baba, M., Hayata, Y. (1997).The changing role of JUAA in Japanese university evaluation. Assessment \& Evaluation in Higher Education, 22 (3), s. 329-335.

Brumfitt, K. (2003). Expert Group on Objective 1.1: Improving The Education of Teachers and Trainers. Group Report on Study Visit to the Teacher Training Agency - London, UK. Theme: Defining Competences and Curriculum in Initial Teacher Training. Web:http://europa.eu.int/comm/education/policies/2010/doc/groupreport-uk en.pdf adresinden 19.12.2005'de alınmıştır.

CHEA (2000). U.S. Accreditation Review. [Judith S. Eaton]. Web: http://www.chea.org/About/accreditation.html adresinden 9.10.2005'de alınmıştır.

CRE (2001). Towards Accreditation Schemes for Higher Education in Europe? Brussel: The Association of European Universities.

Danish Evaluation institute (2003). Quality procedures in European Higher Education an ENQA Survey. ENQA Occasional Papers 5. Helsinki: ENQA. Web:http://www.enqa.net/files/procedures.pdf adresinden 2.10.2005'de alınmıştır.

Durman, M. (2007). Yükseköğretimde Kalite Güvencesi ve Ülkemizdeki Gelişmeler. Eğitim Bilimleri Bakış Açısıyla Eğitim Fakülteleri ve Akreditasyon Çalıştayı. AÜ. Eğitim Bilimleri Fakültesi Yayınları: Ankara. Yayın no: 204

Eaton, S.J. (2005). An overview of U.S. accreditation. CHEA. Web: http://www.chea.org/pdf/overview US accred 8-03.pdf adresinden 12.12.2005'de alınmıştır.

ENQA (2001) [Hämäläinen, K., Haakstad,J., Kangasniemi, J., Lindeberg,T., Sjökng,M.] Quality assurance in the Nordic higher education. ENQA Occational Paper. Helsinki: ENQA. [ISSN K58-1051]

Hood,C. (1991). A public management for all seasons? Public Administration, 69 (1), s. 3-19.

JUAA (2006) Web: http://www.juaa.or.jp/english/main/hyouka.html adresinden 01.03.2005'de alınmıştır. 
Karasar, N. (2003). Bilimsel Araştırma Yöntemi. Ankara: Nobel Yayın.

Kendall, J.S. (2001). A technical guide for revising or developing standards and benchmarks. Washington D.C. US Department of Education Office of Educational Research and Improvement

Köksoy, M. (1997). Yüksekögretimde Kalite ve Türk Yükseköğretimi için Öneriler. Ankara: Hacettepe Üniversitesi Mühendislik Fakültesi Yayınları.

Kısakürek, M.A. (1976). Üniversitelerimizde Yenileşme "Programlar ve Öğretim Açısından”. Ankara: Ankara üniversitesi Eğitim Bilimleri Fakültesi Yayınları. Yayın No: 54.

Kısakürek, M.A. (2007). Çeşitli Ülkelerde Akreditasyon. Eğitim Bilimleri Bakış Açısıyla Eğitim Fakülteleri ve Akreditasyon Çalıştayı. A.Ü. Eğitim Bilimleri Fakültesi Yayınları: Ankara. Yayın no: 204

Kitamura, K. (1997). Policy issues in Japanese higher education. Higher Education, 34(2), s. 141-149.

NIAD-UE (2005). General principles of accreditation. Web: http://www.niad.ac.jp/english/unive/pdf/GeneralPrinciples.pdf adresinden 10.02.2005 tarihinde alınmıştır.

NIAD- UE (2007). Web: http://www.niad.ac.jp/index_e.html adresinden 15.03.2007 tarihinde alınmıştır.

Oakes, T. J.,(1999). A Guide to Organizations İnvolved with Licensing and Certification of Teachers and Accreditation of Teacher Education Programs. ERIC Number: ED437367

Power, M. (1999). The audit society, rituals of verification. Oxford: Oxford University Press.

Shimizu, K., Baba, M., Shimada, K. (2000). The new role of JUAA in Japanese university evaluation. Assessment \& Evaluation in Higher Education, 25(1), s. 51-60.

Ulusal Ajans (2005). Bologna Sürecinin Türkiye'de Uygulanması Projesi 2004-2005 Sonuç Raporu. Ankara: Punto Tasarım Matbaacılık.

UNESCO- CEPES (2004). Quality assurance and accreditation: A glossary of basic terms and definitions. Bucharest: CEPES.

MÜDEK (2007). MÜDEK hakkinda özet bilgiler. Web: http://www.mudek.org.tr/tanit/MUDEK-Ozet_Tanitim(20070802).pdf adresinden 20. 02. 2008 tarihinde alınmıştır.

YÖK (2005). Türk Yüksekögrretiminin Bugünkü Durumu. Web: http://www.yok.gov.tr/egitim/raporlar/raporlar.htm adresinden 07.10.2006' da alınmıştır. 
